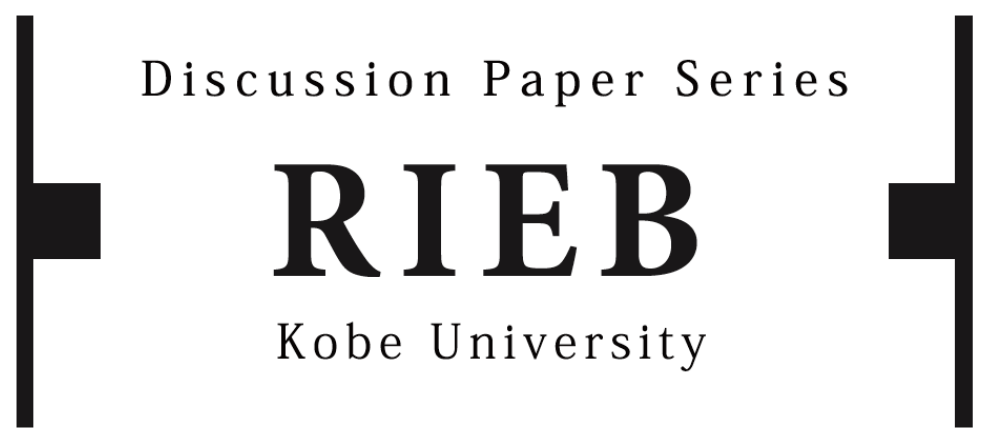

DP2010-19

\title{
The Intranational Business Cycle in Japan
}

\author{
Michael ARTIS \\ Toshihiro OKUBO
}

June 2, 2010

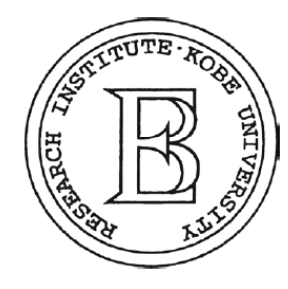

Research Institute for Economics and Business Administration Kobe University 


\title{
The Intranational Business Cycle in Japan
}

\author{
by \\ Michael Artis, Swansea University, and CEPR* \\ and \\ Toshihiro Okubo, Kobe University**
}

December 2009

\begin{abstract}
This paper studies the intranational business cycle - that is the set of regional (prefectural) business cycles - in Japan. One reason for choosing to examine the Japanese case is that long time series of relatively detailed data are available. A Hodrick-Prescott filter is applied to identify cycles in annual data from 1955 to 1995 and bilateral cross-correlations of prefectural GDPs are calculated for all pairs of prefectures, in our results we find fairly high cross-correlations. The paper then turns to an econometric explanation of the cross-correlation coefficients in the augmented gravity model framework. Two prefectures with similar GDPs and a shorter distance between them lead to business cycle synchronization whilst those with larger regional gaps in factor endowments (capital, labor and human capital) result in more idiosyncratic business cycle.
\end{abstract}

JEL Classification : E32, F41, R11

Keywords: Intranational business cycle, Hodrick-Prescott filter, Optimal Currency Area, Gravity Model, Heckscher-Ohlin theorem.

* Welsh Assembly Government Visiting Research Professor, Department of Economics, University of Swansea, Singleton Park, SA2 8PP, Swansea, UK

E-mail:Michael.Artis@manchester.ac.uk

**Associate Professor, Kobe University, Research Institute for Economics and Business

Administration (RIEB), Rokkoudai-cho 2-1, Nada-ku, Kobe, 657-8501, Japan. E-mail:

okubo@rieb.kobe-u.ac.jp

Acknowledgments: The work underlying this paper was largely carried out when the authors were at the University of Manchester. The authors are grateful to Tommaso Proietti, Len Gill, George Chouliarakis, Pierre M. Picard, Denise Osborn and participants at seminars in Kobe and Manchester Universities for their advice along the way. They are also grateful to Kyoji Fukao and Hyeog Ug Kwon for providing data sets and Robert O’Neill for excellent proof reading. 


\section{Introduction}

The intranational business cycle is the set of business cycles that characterize the regions of a country. Although less commonly studied, analysis of intranational business cycles offer a useful benchmark for comparison with results obtained from international business cycle analysis. ${ }^{1}$ As an example, issues of adjustment and of consumption-risk sharing, and more generally many of the predictions of real business cycle (RBC) theory, which have been investigated at the international level, can also be analyzed at the intranational level, often with different results. Such differences provide a challenge for those attempting to formulate an explanation.

Intranational cycles have been studied in the past in connection with propositions in the optimal currency area (OCA) literature, particularly with respect to risk-sharing mechanisms (see Wincoop, 1995; Iwamoto and Wincoop, 2000 for leading examples). However the OCA perspective with risk-sharing mechanisms is not the only one that should be important in studies of the intranational business cycle. Indeed, as shown below, many of the variables that allegedly determine the degree of international business cycle convergence, can be seen to have little effect in the intranational context.

We have chosen to investigate the intranational business cycle in Japan, this allows us to make use of a relatively lengthy and comprehensive time series of regional accounts and factor endowment records which exists for Japan's 47 prefectures. $^{2}$ It is useful to note that Japan is completely divided into 47 prefectures, which are roughly equivalent to NUTS 2 regions.

This paper studies intranational business cycles by using Japanese prefecture data sets. We aim to investigate how highly correlated intranational business cycles are, which regional factors affect intranational business cycle synchronization, and then to discuss how such factors compare with those considered in the international business cycle literature. The regional context of the intranational cycle draws attention to the need to take up some of the themes and insights contained in traditional (Heckscher-Ohlin) and new trade (the gravity model) theory.

\footnotetext{
${ }^{1}$ Of the handful of previous studies of the intranational business cycle the better-known are those by Wynne and Koo (2000), Hess and Shin (1997 and 2001) Del Negro (2001) and HM Treasury (2003). A more recent example is Partridge and Rickman (2005).

${ }^{2}$ See Table A for 47 Japanese prefectures list for details.
} 


\section{Related Literature and Our Paper}

A key factor for business cycle synchronization is trade, in particular, interregional trade is much more frequent than international trade as shown in McCallum (1995) by the gravity model. ${ }^{3}$ The gravity equation explains active intra-industry trade between two regions with similar economies (GDPs) and geographical proximity (distance), which is theoretically supported by the New Trade Theory (Helpman and Krugman, 1985). ${ }^{4}$ On the other hand, inter-industry trade is still dominant in the current world (Brulhart, 2009). The other type of trade explained by traditional trade theory, specifically the HeckscherOhlin theorem, is inter-industry trade in which capital (labor) abundant regions export capital (labor) intensive goods. Differently endowed economies engage inter-industry trade through specialization in sectors in which they have abundant factor endowments. ${ }^{5}$

Trade is crucially linked with international business cycle synchronization, which is our main interest. ${ }^{6}$ This line of thought was effectively initiated by Frankel and Rose (1998), who showed that the traditional criteria for an optimum currency area might, in effect, be endogenous. The traditional criteria could be read as trading off the benefits of additional trade against the cost of relinquishing monetary sovereignty and the associated benefits of stabilization policy. If it could be shown that the additional trade itself led to greater business cycle synchronization then the costs of relinquishing monetary sovereignty would be reduced. A set of subsequent studies investigates the generalization and sophistication of the initial relationship uncovered by Frankel and Rose (1998) (Frankel and Rose, 2001, Rose, 2000 and de Haan, et al. 2008), arguably the most complete exercise in this vein was the paper by Gruben et al. (2002). A number of issues were raised in the course of this work, first and foremost being how the trade-GDP relationship should be rationalized. As Gruben et al. (2002) discuss, the cycle can be viewed as a response to a shock, the prevalence of intra-industry trade between countries

\footnotetext{
${ }^{3}$ McCallum (1995) found that Canadian inter-provincial trade is 22 times as large as US-Canada trade, referred to as the border effect. See Okubo (2004) for the Japanese interregional trade case. Bergstrand (1985) explained the gravity model in the framework of new trade theory.

${ }^{4}$ Hummels and Levinsohn (1995) found empirical evidence of active intra-industry trade among developed countries and suggested the importance of distance between trade partners. Helpman (1987) empirically showed that developed countries with similar GDPs tend to have a high proportion of intraindustry trade.

${ }^{5}$ Evenett and Keller (2002) empirically tested the relationship between intra-industry trade and interindustry trade in terms of factor endowment differences.

${ }^{6}$ Traditional OCA theory, as identified with Mundell (1961), points towards a trade-off between trade and integration benefits against loss of monetary sovereignty, the latter being assumed to imply a loss of regional stabilization policy benefits. A high correlation between regions' business cycles resolves the trade-off because the common monetary policy of a currency union then appears appropriate for all the regions.
} 
demonstrates their common exposure to shocks (of technological or of "taste" origin) and hence the likelihood of a synchronization in cyclical experience. ${ }^{7}$ On the other hand interindustry trade suggests a degree of specialization likely to result in a high frequency of idiosyncratic shocks, ultimately reflected in low business cycle cross-correlations. The study of the international business cycle has also led to the reflection that differences in the propagation mechanism, including differences in policy response and even linguistic and genetic differences (e.g. Spolaore and Wacziarg, 2006), are liable to produce different business cycles. It is clear that many of these elements have no relevance in the setting of an intranational cycle, where institutions and markets important to the propagation mechanism are "national" in character and scope. This seems especially true in the case of Japan which is an ethnically homogeneous and highly centralized nation exemplified by the fact that institutions, product/factor markets, financial and taxation systems are fairly uniform across regions. At the same time, for the prefecture system we consider here prefectural trade data do not exist, although there exists regional (aggregated at a level higher than prefectural) trade data available, as discussed below. Nevertheless, as will become clear below, the basic idea of choosing explanatory variables that might reasonably proxy a common, or idiosyncratic, vulnerability to shocks, which should then predispose regions towards high or low cross correlations respectively, are ones with potential relevance for the problem in hand. The notion that any heavy flow of trade is likely to imply a common fate in the face of external shocks suggests that any variables that might proxy trade, as for example those suggested by the gravity model will prove useful explanatory information.

An advantage of using the data employed in this paper is that we are able to study the long-run regional data with many kinds of variables, as our data spans over 40 years, from 1955 to 1995 in 47 prefectures. The reason for excluding the data from 1995 onwards from our sample is that the impact of foreign direct investment (FDI) and foreign outsourcing to Asia were negligible before the mid 1990s. From the mid-1990s onwards the Asian economy affected the Japanese national economy and thus regional business cycle might be synchronized with those of other Asian countries rather than other Japanese regions. Thus the current decade is required to draw attention on Japanese regions as well as foreign countries. However most manufacturing firms and plants located inside Japan before the mid-1990s operated without substantial Asian FDI,

\footnotetext{
${ }^{7}$ See Kenen (2000), Firdmuc (2002), Imbs (2004), Caldéron et al. (2007), Inklaar et al. (2008) for more discussion.
} 
foreign outsourcing and hollowing-out. For this reason our sample period beginning several decades before the mid-1990s, seems appropriate for discussing regional business cycle synchronization in Japan.

Our main findings are that 1) Japanese prefectures have fairly high positive business cycle correlations over several decades, however the imbalance of economic growth across regions and factor movements in earlier years exacted a toll in reducing the synchronicity of the regional cycles during such periods. The high cross-correlations reflect the homogeneity of Japanese society in aspects such as legal, political and economic institutions, culture, and language and support an optimal currency area argument. 2) Augmented gravity model variables have a considerable explanatory power in the cross-correlations. Higher GDPs and shorter distance between prefectures increase are shown to increase correlations. 3) The variables based on the Heckscher-Ohlin theorem also have explanatory power. Larger capital-labor ratio gaps and larger human capital gaps reduce business cycle synchronization driven by active inter-industry trade in sectoral specialization across regions. In particular, recent decades (1980s-1990s) see increased explanatory power in factor endowment differences.

This paper is organized into 7 sections, in the next section we discuss ways to identify the cycle and provide some comparisons with other intranational cycles, we then show that the cohesion of the Japanese intranational cycle in comparison with other countries. Subsequent sections study how cross-correlations can be explained by regional factors (sections 3, 4 and 5). We also consider that another purpose of an intranational cycle investigation such as this is to measure and identify the extent and nature of the consumption risk-sharing mechanisms that exist in section 6. Finally, section 7 sets out some conclusions.

\section{Identifying the Business Cycle}

Traditional business cycle analysis recognizes two types of cycle. There is the "classical" cycle, which can be recognized from the fact that it involves an absolute decline in economic activity from the peak and an absolute rise in activity from the trough. The NBER for the US and the CEPR for the Euro Area provide chronologies of such cycles. Clearly such cycles do not exist in growth economies and they are relatively rare for European economies and Japan. The second type of cycle is a deviation or growth (occasionally growth rate) cycle where the underlying idea is that the business 
cycle is identified as a cycle relative to a trend. It is the concept of the deviation cycle that we utilize in our investigation, consequently we need to use a filter to measure the trend so that the cycle, measured as deviations from the trend, can be identified. In our case, where the original data are annual, there is a reasonable presumption that highfrequency noise, such as seasonal effects, is already filtered out. On this basis we use a Hodrick-Prescott (HP) filter with a "lambda" value (dampening factor) set at 6.25, following the suggestion of Ravn and Uhlig (2002), this corresponds to a maximum periodicity of the cycle of 10 years just as the popular "lambda" value of 1600 does for data observed at a quarterly frequency. ${ }^{8}$ The filter is applied to the log of the GDP series for each prefecture and for Japan as a whole. ${ }^{9}$ Figure 1 shows the national cycle identified in this way, alongside it the cycles for Tokyo, Osaka (the second largest city) and for Aichi (the capital of which is Nagoya, the third largest city in Japan). Perhaps not surprisingly the cycle for Tokyo closely follows that for Japan, Tokyo itself accounts for 15 to 20 per cent of Japanese GDP and the wider Tokyo Area for 30 per cent over recent decades. ${ }^{10}$ It is clear from Figure 1 that Osaka and Aichi (Nagoya) follow the national cycle less closely, with more deviations evident. ${ }^{11}$

Our preferred tool of analysis from here on is the bilateral cross-correlation between the cyclical deviates for any (and all) pairs of prefectures. When econometric explanation is attempted we use Fisher's z-transformation of this cross-correlation of HP-filtered GDPs to remove the potential of a limited dependent variable problem. ${ }^{12}$ Bilateral crosscorrelation tools can be used to compare the Japanese intranational cycle with that for the US (US gross state product (GSP) data being used) and with that for a synthetic Euro Area (the data are just the data on the national business cycles for the countries that eventually formed the EuroArea-12, prior to the entry of Slovenia into the Euro Area $)^{13}$. US intranational data have been used before, as providing a presumptive benchmark for a

\footnotetext{
${ }^{8}$ There remains a degree of controversy about the procedure, as exemplified most recently in the paper by Meyers and Winker (2005), following earlier papers by Harvey and Jaeger (1993), Burnside (1998) and Canova (1998) among others. However, an effective counter criticism can be found in Kaiser and Maravall $(2001,2002)$.

${ }^{9}$ We test whether detrended GDP variables are stationary by using unit root tests. As a result of ADF tests, all 47 series of the variable are stationary. The report of the results is omitted to save the space.

${ }^{10}$ The Tokyo Area is defined in our paper as Tokyo, plus its adjacent prefectures of Kanagawa, Saitama and Chiba. In terms of population size Tokyo accounts for less than 10 per cent in recent decades, but the Tokyo Area has 30 per cent.

${ }^{11}$ Generally more localized regional business cycles might be expected to be more volatile than the aggregate national cycle as more localization implies more specialization.

${ }^{12}$ See the section "definitions" in the Data Appendix for Fisher's z-transformation.

${ }^{13}$ The Euro-12 countries are composed of Austria, Belgium, Finland, France, Germany, Greece, Ireland, Italy, Luxembourg, the Netherlands, Portugal and Spain. See the Data Appendix for data source.
} 
currency area to reach (see Hess and Shin, 1997; Wynne and Koo, 2000; HM Treasury 2003), whilst the countries forming the Euro Area have indeed formed a new currency union. The top and middle panels of Figure 2 show the distribution of bilateral cross correlations of the cyclical deviates for the 50 States over the periods 1990-1997 and 1997-2005 whilst the bottom panel of Figure 2 does the same for the EuroArea-12 countries over the period 1975-1995. Turning to GDP correlation across Japanese prefectures, five panels of Figure 3 provide the same information for Japan over 4 separate sub-periods (1955-1964, 1965-1974, 1975-1984, and 1985-1995) and over the entire period. It is clear that the Japanese distribution changed shape considerably over the period, reflecting what we know to be some turbulent periods of structural change. The more recent distributions suggests a greater degree of cohesion, exemplified by fewer or no negative values and a clustering around high positive values, than can be found in the earlier periods or for the other countries.

Moran's I statistic, which tests for spatial autocorrelation (Moran, 1948, 1950), indicates an absence of this phenomenon throughout the sample period, values of these indices are provided in an Appendix. ${ }^{14}$ As shown in Figure A a value of almost zero for Moran's I (approximately 0 to -0.1) implies that GDP fluctuations are spatially random and thus have no positive or negative spatial correlations with neighboring prefectures. The absence of spatial autocorrelation tells us that we need not use spatial econometrics concepts to explain cross-correlations. ${ }^{15}$

\section{Explaining the Cross-correlations}

In this section we study the pattern of cross-correlations that we identified in the regional business cycle data in Section 2. In so doing we note that there are some other important considerations to be taken account of here. First, the incidence of structural change across Japanese regions suggests that it would be unreasonable to treat the period

\footnotetext{
${ }^{14}$ Another statistic for spatial autocorrelation is Geary's C statistic. The result is consistent with that of Moran's I and indicates no spatial autocorrelations. To save the space, the result is not reported.

${ }^{15}$ In Moran's I statistic if we observe a value of $+1(-1)$, then the same (different) characteristic regions are perfectly clustered (dispersed). A value of zero indicates a random spatial pattern (i.e. there is no spatial autocorrelation). If we observe spatial autocorrelations through Moran's I statistic, then we have two possibilities and distinguish between them by using spatial econometric techniques. The first is spatially correlated error terms, in which the solution comes from the inclusion of the spatial lag of the dependent variable. The other is residual or nuisance spatial autocorrelation, which may arise from the omission of relevant variables or from measurement errors (See Anselin, 1988 for more details).
} 
as homogeneous. ${ }^{16}$ We therefore divide the sample into four sub-periods of ten years each and average the variables over these decades. Secondly, we use GMM, nominating as instruments one period lagged values of our independent variables with some identification tests. ${ }^{17}$ Thirdly, the left hand side dependent variable, the set of bilateral cross-correlation coefficients between prefectures $\mathrm{i}$ and $\mathrm{j}$ at time $\mathrm{t}, \rho_{i j t}$, is potentially a limited dependent variable as the values are bounded between -1 and +1 ; to overcome the potential bias involved in not recognizing this we apply Fisher's " $z$ " transformation to the data, defined as $\sigma_{i j t} \equiv \frac{1}{2} \log \left(\frac{1+\rho_{i j t}}{1-\rho_{i j t}}\right)$. In this paper the transformed cross-correlation of HP filtered real GDPs, $\sigma_{i j t}$, is regressed on the independent variables. ${ }^{18}$ Following the argument above we consider as independent variables the following; product of twoprefecture real GDPs, the GDP per capita gap between two prefectures, the capital-labor ratio gap, infrastructure per-capita gap, human capital gap, area, geographical distance, a dummy for adjacency, manufacturing ratio, and manufacturing specialization index. ${ }^{19}$ One period lagged values of these are used as instruments in GMM estimation.

As discussed in Frankel and Rose (1997) and Gruben et al.(2002), the expected signs of real GDP and distance are positive and negative respectively, because the gravity equation indicates that two economies with higher GDPs and smaller intermittent distances leads to synchronization of business cycles through active intra-industry trade. The variables of capital-labor ratio gap and human capital gap are expected to be negative sign. The Heckscher-Ohlin type of inter-industry trade increases idiosyncrasies in business cycles. As a proxy for the capital-labor ratio difference, the gravity equation sometimes uses the GDP per capita gap (Hummels and Levinsohn, 1995). Thus, the sign

\footnotetext{
${ }^{16}$ The reason for taking 4 sub-samples is that almost every ten years from 1955 Japan experienced critical changes. For instance, the high-speed transport system and highway networks were first developed in the mid 1960s, and then a rapid economic growth period prevailed until the middle of the 1970s. Manufacturing sectors shifted to machinery after the oil crisis after the middle 1970s; then there was the Plaza Accord of 1985, which appreciated the Japanese yen, promoting Japanese FDI and international trade. The highway networks and transport system were spread all over Japan and were completed in the middle of the 1980s. Along with globalization this powerfully affected firm location within Japan. See Fujita and Tabuchi (1996) for regional and sectoral structural changes in the post-war Japan.

${ }^{17}$ General considerations suggest that there will be a substantial amount of endogeneity in the data, which requires the use of an appropriate estimation technique. Thus we use the 2-step GMM with underidentification test using the Anderson Cannon correlation LM statistic, the weak identification test of Cragg and Donald and the overidentification test using Sargan Statistic.

${ }^{18}$ Even if we use nominal GDP, all main results as shown below can keep the same.

${ }^{19}$ These are all more or less self-explanatory but a detailed definition of each appears in the Data Appendix.
} 
of GDP per capita should be also negative. The variable recording the infrastructure (per capita) gap is expected to be negative or positive, depending on policy targets and outcomes, possibly because the practice of successive Japanese governments has been to reward lagging areas with substantial public sector infrastructure investment (per capita), so that the variable acts as a "branding" or for other reasons. Finally, the variables relating to the manufacturing ratio and manufacturing specialization index reflect how manufacturing is crucial in the economy and thus are expected to be positive particularly in early years as Japan experienced a drastic growth in the 1960s and 70s, during which manufacturing played a crucial role in the business cycle. When two prefectures have a large proportion of manufacturing, business cycle is more synchronized.

We now investigate whether these assumptions are borne out in an empirical investigation. Given the commonly held association between trade and business cycle synchronization we commence with a model which is based on the gravity model of trade. Here we can consider GDP and distance as variables, as in the simple model, supplemented by a dummy for a shared border and area. Starting with the classical gravity model, the first set of results (see the first panel of Table 1) yield the expected positive sign on GDP products and the expected negative sign on the distance parameter. This indicates that larger intra-industry trade across prefectures leads to common vulnerability to shocks, thus resulting in business cycle synchronization. Interestingly, the magnitude of the distance parameter declines over time before becoming insignificant. This indicates that decreased transport costs and weaker geographical aspects have affected business cycle synchronization through time.

The second set of results, shown in the second panel of Table 1, include results regarding an additional variable, namely the GDP per capita gap, which is the absolute difference in GDP per capita between prefectures $\mathrm{i}$ and $\mathrm{j}$. This variable is used as a proxy for factor endowment difference and the wealth gap. As expected, the parameter on this variable is significantly negative in all periods while the GDP and distance parameters remain positive and negative respectively. The results indicate that regional difference in factor endowments should be further investigated.

To investigate the impact of factor endowment differences in accordance with the Heckscher-Ohlin theorem, the "gravity model" variables are supplemented by factor endowment variables, i.e. capital-labor ratio gap, human capital gap and infrastructure per capita gap. As expected, in the results reported in the third panel of Table 1 the capital-labor ratio gap between two prefectures has a significantly negative relationship 
with GDP cross-correlations in the latter two periods and the human capital gap is significantly negative in only the last period. In later periods endowment gaps have stronger explanatory power. Both terms represent a Heckscher-Ohlin type of interindustry trade, which leads to idiosyncratic vulnerability to shocks and results in low cross-correlations. Hence inter-industry trade, as well as intra-industry trade, plays a significant role in explaining business cycle correlations in recent periods. On the other hand the infrastructure per capita gap parameter is significantly negative in the first period, albeit the late two periods cannot see. Prefectures with similar levels of infrastructure are more likely to link with each other, however prefectures with high levels of per-capita infrastructure are less likely to link with those endowed with a low level of infrastructure.

In the fourth and fifth panels of Table 1 the explanatory variables are further augmented by variables relating to the role of manufacturing in the prefecture. The prefectures percentage of national manufacturing, CL, has a significantly positive sign, regardless its insignificance in the last period. Prefectures with a high percentage of manufacturing are likely to be more correlated in GDP. The coefficient on the manufacturing specialization index, CV, changes sign over the periods. Similar to CL, $\mathrm{CV}$ is significantly positive before becoming insignificantly negative in the last period. This implies that manufacturing substantially contributed to business cycle correlation in the 1960s to the 1970s, whereas other sectors such as service and non-manufacturing played a role in leading business cycle correlation after the mid $80 \mathrm{~s}$, consistent with the experience of Japanese manufacturing growth. Finally, we investigate model specifications related to instruments. All panels of Table 2 report the values of an underidentification test (Anderson Cannon correlation LM statistic), Cragg Donald's weak identification and the Sargan Statistic for overidentification test below the estimation results. Based on the results of these tests all of our model specifications are reasonable.

To summarize, the arguments of a simple gravity-style trade model, as represented here GDP and simple distance, and the Heckscher-Ohlin model, as represented by the capital-labor ratio gap and the human capital gap, are the most reliable sources of business cycle differences across the prefectures.

\section{Sensitivity Analysis}


One of the key factors for intranational business cycle synchronization is interregional trade. Unlike in the international business cycle literature there does not exist data recording trade between the 47 prefectures thus we cannot directly measure the impact of trade, and so use the Gravity type estimations in accordance with New Trade Theory. Japan, however, does have regional trade data sets in the Inter-regional input-output (IO) Table assembled by the METI (Ministry of Economy and International Trade of Japan). Although the data are published every five years (data are not reported per annum) and are not at prefecture level, but for 8 regions, it is worthwhile to test at the regional level. Roughly, 8 Japanese regions almost correspond to a NUTS 1 region. ${ }^{20}$

Using this data, we estimate the impact of trade on intranational business cycle, however, since we aggregate the 47 prefectures to 8 regions, we are forced to abandon some independent variables such as factor endowment gaps and the manufacturing specialization index, because each region includes big cities, rural areas. Similarly regions may be a combination of manufacturing (capital abundant), service districts (human capital abundant) and agricultural (labor/land abundant) areas. Regions are much economically homogenous than prefectures. As a result of less sectoral specialization at the regional level, gaps of factor endowment ratio and the infrastructure per capita substantially decline between the regions. ${ }^{21}$ Thus this section adopts the original gravity model and considers whether GDP and distance can be good proxies for trade. Here, trade is measured by the bilateral trade in GDP of two regions, i.e. Trade $\equiv \frac{\text { Trade }_{i j}}{G D P_{i}^{*} G D P_{j}}$, where Trade $_{i j}$ denotes bilateral trade flows between region $\mathrm{i}$ and $\mathrm{j}$. An alternative measure is trade intensity, given as TradeIntensity $\equiv \frac{\text { Trade }_{i j}{ }^{*} \text { Total Trade }}{\text { Trade }_{i} * \text { Trade }_{j}}$, where Total Trade denotes all interregional trade flows and Trade $_{i}$ is all bilateral trade in region $i$. In this regional analysis, as the number of observations is smaller than in the prefectural analysis, we use instrumental variable (IV) panel regressions. As in the prefectural regressions instrumental variables are the independent variables lagged one period. Table 2 reports the results for these regressions, the first column reports the result of gravity estimation, which is consistent with the prefectural level estimations. The second and third columns

\footnotetext{
${ }^{20}$ See Table A for the classification of 8 regions.

${ }^{21}$ We tried to test some regional estimation using capital-labor ratio and human capital gap, but results are insignificant in all cases.
} 
report the results for trade variables instead of GDP and distance. The interregional trade measures are significantly positive, thus we conclude that larger interregional trade promotes interregional business synchronization, consistent with the findings of McKinnon (1963), and the gravity model variables are a good proxy for trade variables. Our regional level results support our prefectural results based on an augmented gravity model.

\section{Discussion}

Our results exhibit good fits to augmented gravity equations, higher GDPs and smaller geographical distance increase the correlation between prefectures. The relevance of the gravity equation in explaining business cycle convergence was initially highlighted in the empirical OCA literature as it was shown that active (intra-industry) trade between countries (Frankel and Rose, 1997; 1998) and a high openness of trade (McKinnon, 1963) synchronize business cycles. Our results show that these hypotheses from international business cycle studies are applicable to intranational business cycles. They confirm, to an extent, that the set of Japanese prefectures constitutes an optimal currency area

We have also provided evidence that differing factor endowments reduce business cycle synchronization. In particular the recent years there is a significant impact of differing factor endowment gaps on synchronization. The 80s and early 90s saw the fragmentation of production process across Japanese regions and increased intermediate input trade and parts and component trade, in which capital (labor or human) abundant region specializes in capital (labor or human capital) intensive production process in the mechanism of the Heckscher-Ohlin theorem. This might substantially amplify the impact of factor endowment gaps on business cycle correlations in the recent years.

We also investigated the role of the infrastructure per capita gap, the coefficients on the variable are significantly negative in the 1960s and 70s, i.e. there is a negative impact of a public investment gap on business cycle synchronization. That is, two prefectures with higher infrastructure per capita in rural areas have a higher correlation, whilst these prefectures have a lower correlation with prefectures with lower infrastructure. In Japan public capital / infrastructure per capita is higher in rural areas and lower in cities in order to reduce the core-periphery wealth gap. In the 1970s Japanese governments invested in public capital through fiscal policy in rural areas. This implies that the development of 
industrial infrastructure, including highways, road networks, ports and airports, in rural areas does not greatly contribute to business cycle synchronization between core and periphery areas. Instead the investment fortifies connections with other rural areas and boosts the correlation with them. This suggests a paradox, that more public capital investment in rural areas by the central government reduces, or does not increase, business cycle synchronization. If we supplant our findings on this point to a European setting, it could be inferred that EU Structural Funds, in particular public investments in poor peripheral regions, are not appropriate, and might actually be harmful, in the sense of reducing business cycle synchronization, which is harmful to an optimal common currency area.

\section{Additional Discussion-- consumption risk-sharing}

A stylized fact that comes strongly out of the data is that institutions in Japan appear to permit a high degree of consumption risk-sharing. We took the consumption data for the 47 prefectures in our working sample and filtered them in the same way as the GDP data. We also calculated bilateral cross-correlations of the cyclical deviates of consumption for each pair of prefectures. Figure 4 plots these consumption crosscorrelations against the GDP cross correlations. RBC theory predicts that (in the presence of complete asset markets) consumption-smoothing should result in consumption cross-correlations which are higher than the corresponding output correlations at business cycle frequency. Based on the graphical evidence displayed in Figure 4 this would lead us to expect that the majority of the observations would lie below the 45 degree line, as they do. This provides a counter-example to the well-known “consumption/output" anomaly first uncovered by Backus et al. (1993). In their study, and subsequent work, the international evidence points to consumption correlations being lower than output correlations. The contrary finding lends weight to the presumption that Japanese prefectures constitute a standard for an optimal currency area, but leaves open the question of the quantification of the channels through which this is achieved, an issue which will be the subject of a subsequent paper, (see Iwamoto and Wincoop (2000) for further discussion). The fact that the channels (and degree) of consumption risk-sharing may vary across countries requires documentation and provides a natural complement to the resolution of the puzzle that international capital mobility seems to have increased 
drastically without affecting conventional measures of risk-sharing between countries (see Artis and Hoffmann, 2006)

\section{Conclusions}

In this paper we have identified the intranational business cycle in Japan using GDP data for prefectures over the period 1955-1995. In the first section we compared it with those for the US and the Euro Area. In the Japanese case, examined in this paper, the degree of business cycle synchronization within the country emerges as strikingly high by comparison with that for the US and the Euro Area.

The paper moves on to explain the patterns of business cycle synchronization summarized in the set of bilateral cross-correlations. Our econometric explanation of the pattern of bilateral cross-correlations between the prefectures of Japan draws heavily on a feature of earlier international cross-correlation work, the idea that trade models specifically the gravity model and the Heckscher Ohlin trade model - can help to explain business cycle associations. We find that variables that can be associated with gravity model explanatory variables, such as GDP and distance, and with Heckscher-Ohlin variables, like the capital labor ratio gap and human capital gap, supplemented by endowment variables and other variables are highly significant in explaining the bilateral business cycle cross-correlation coefficients in a GMM estimation framework. This is gratifying from several points of view: it underscores the remarkable versatility of the gravity model and allows us to integrate our knowledge of the development of the Japanese economy with modern trade theory.

A feature of working currency unions is that some mechanisms usually exist to facilitate consumption risk-sharing, we notice that overall risk-sharing between the prefectures is a more prominent phenomenon than the widely reported consumptionoutput puzzle would lead us to expect, however its precise measurement and explanation remain a matter for investigation in a future paper.

\section{Data Appendix}

The number of Japanese prefectures became 47 after the Okinawa prefecture was returned from the United States in 1972. Due to data availability problems for Okinawa 
Prefecture before 1972 and its position as both a geographical and economic outlier our estimation sample is restricted to the 46 mainland prefectures from 1955 to 1995. Many prefecture data sets for factor endowment data are taken from Fukao and Yue's "Japanese prefecture data base"(Hitotsubashi University, Tokyo, Japan) (http://www.ier.hitu.ac.jp/ fukao/japanese/data/index.html) and Fukao and Yue (2000). The GDP data set for the12 EU nations for the HP-filtered GDP cross-correlations in the bottom panel of Figure 2 is taken from World Development Indicator (Edition September 2006, World Bank). GDP is constant 2000 US dollars. The US GSP (gross state product) data sets for the autocorrelation in the top and middle panels of Figure 2 are taken from Bureau of Economic Analysis, US Department of Commerce (http://www.bea.gov/regional/index.htm\#gsp). The unit of real GSP is millions of chained 2000 dollars.

\section{Definitions}

\section{The dependent variable}

The bilateral cross-correlation of cyclical deviates from HP-filtered real GDPs in two prefectures ( $\mathrm{i}$ and $\mathrm{j}$ ) in four sub-sample periods is transformed by Fisher's $\mathrm{z}$ transformation. The transformation is intended to expand the limited variation (from -1 to 1) in the cross correlation measure. Fisher's z transformation is a one-by-one mapping from a variable, $\rho$, to a variable $\sigma$, utilizing a uniformly increasing monotone function, defined as $\sigma=0.5 \ln \left(\frac{1+\rho}{1-\rho}\right)$ for $-1<\rho<+1$.

\section{The independent variables}

All the variables are related to prefectures $i$ and $j$, corresponding to the correlation of the dependent variables. The variables are the average values in each sub-sample period. In GMM estimations, variables lagged one period are used as instruments. Thus, all dependent variables in period 1 (1955-1964) are only used as instruments.

GDP: GDP denotes the logarithm of the product of real GDPs in prefectures $i$ and $j$. Nominal GDP is taken from Fukao and Yue's "Japanese prefecture data base"(Fukao and Yue, 2000). Since there is no long-run GDP deflator correspondent to our sample, our real GDP is derived by using a national level GDP deflator (base year 1990). Here we assume each prefecture encounters a similar price index, alternatively we assume that 
intertemporal change in prices is much more relevant and more important than regional price difference.

Gap: Absolute difference of log of GDP per capita between two prefectures.

KL: This is the variable of the logarithm of the capital-labor ratio gap between prefectures $\mathrm{i}$ and $\mathrm{j}$. This is private sector capital and labor denotes the work force. Both capital and labor are taken from the Fukao and Yue data sets.

Infra: This variable is the difference of the log of industrial infrastructure per capita in two prefectures. Industrial infrastructure is a part of public capital formation, the source is the Fukao and Yue data sets.

Human: this denotes the absolute difference of the human capital index calculated by Fukao and Yue. The indices are derived from relative wages conditioned on gender and educational level. The index is normalized to one for male workers with less than junior high school levels of education. Higher values express greater human capital endowments.

$\mathbf{C L}$ : this is the summation of the manufacturing ratios of two prefectures. The ratio is defined as the manufacturing worker population of prefecture $i$ as a proportion of the total number of Japanese manufacturing workers, $C L_{i}=\frac{\text { Manufacturing }}{\sum_{i} \text { Manufacturing }}$. This represents prefecture i's share of manufacturing in Japan. The data are taken from Manufacturing Census.

CV: this denotes the summation of two prefectures' manufacturing specialization index. The index is defined as the deviation of manufacturing worker in all working force (e.g. agriculture, manufacturing and service sectors) in prefecture $\mathrm{i}$ from the average in Japan, i.e. $C V_{i}=\frac{\text { Manufacturing }_{i}}{\sum_{i} \text { Manufacturing }}-\frac{\text { WorkForce }_{i}}{\sum_{i} \text { WorkForce }_{\text {Mon }}}$. When the value takes a higher positive number, prefecture $i$ is relatively specialized in manufacturing, otherwise prefecture $\mathrm{i}$ is relatively specialized in service and agriculture, this reflects a comparative advantage in manufacturing. The data are taken from Manufacturing Census.

Area: Area is the logarithm of the product of two areas $\left(\mathrm{km}^{2}\right)$.

Dist: Distance is the logarithm of the geographical distance between two prefectures. The distance is measured between the capitals of the prefectures $(\mathrm{km})$.

Neighbor: Dummy for shared border between two prefectures. 
Trade: The data are taken from the Inter-regional IO Table published by METI. The Table has been published every five years since 1960. The trade data of 1960 are for the first period (1955-1964), which is solely used as an instrumental variable in the second period, the trade data of 1970, 1980 and 1990 are used for our sample period of 1965-1974, 1975-1984 and 1985-1995, respectively.

\section{Appendix: Moran's I statistic (Spatial Autocorrelation)}

This statistic is aimed at studying (global) spatial autocorrelation in terms of GDPs across prefectures (Moran, 1948, 1950). Figure A shows Moran's I statistic to test spatial autocorrelation statistic in HP filtered GDP for 47 prefectures from 1955 to 1995, which is bounded in value between -1 and +1 . The formula of Moran's I is given as

$$
I=\frac{\sum_{i=1}^{n} \sum_{j=1}^{n} W_{i j}\left(X_{i}-\bar{X}\right)\left(X_{j}-\bar{X}\right)}{\sum_{i=1}^{n} \sum_{j=1}^{n} W_{i j} \frac{1}{n} \sum_{i=1}^{n}\left(X_{i}-\bar{X}\right)^{2}}
$$

where geographical distance is used as the weight matrix W. Values for the I-statistic closer to 1 indicate clustered (spatially concentrated) data points with similar characteristics, whilst values close to -1 imply gathering data points with totally different characteristics. When the value is zero, it is randomly distributed in space, i.e. there is no spatial pattern in the distribution of characteristics.

\section{References}

Anselin,L. (1988) Spatial Econometrics: Methods and Models Kluwer Academic Publishers, The Netherlands.

Artis, M and M. Hoffmann (2006) "The Home Bias and Capital Income Flows between Countries and Regions", CEPR DP 5691.

Backus, D.K., P.J. Kehoe and F.E. Kydland (1993) "International Real Business Cycles: theory and evidence", NBER Working Paper, No. 4493.

Bergstrand, J. (1985) "The Gravity Equation in International Trade: Some Microeconomic Foundations and Empirical Evidence." The Review of Economics and Statistics, Vol. 67, No. 3, 474-481.

Brulhart, M (2009). "An Account of Global Intra-industry Trade, 1962-2006," The World Economy, vol. 32(3), pp. 401-459. 
Burnside C. (1998), “Detrending and business cycle facts: A comment”, Journal of Monetary Economics, 41(3), 513-532.

Calderon, C, A.Chong, and E.Stein, (2007). "Trade intensity and business cycle synchronization: Are developing countries any different?," Journal of International Economics, vol. 71(1), pages 2-21.

Canova F. (1998), “Detrending and business cycle facts: A user's guide”, Journal of Monetary Economics, 41(3), 533-540.

de Haan, J., R. Inklaar and R. Jong-A-Pin, (2008). "Will Business Cycles In The Euro Area Converge? A Critical Survey of Empirical Research," Journal of Economic Surveys, vol. 22(2), pp. 234-273.

Del Negro, M (2002) "Asymmetric Shocks among U.S.states", Journal of International Economics, 56 (2): 273-297.

Evenett, S. J. and W. Keller (2002), "On Theories Explaining the Success of the Gravity Equation", Journal of Political Economy, 110, 2, 281-316.

Fidrmuc, J. (2004) "The Endogeneity of the Optimum Currency Area Criteria, Intraindustry Trade and EMU Enlargement”, Contemporary economic policy, 22, $1-12$.

Frankel, J. and A.Rose (1997) "Is EMU more justifiable ex post than ex ante?", European Economic Review, 41, 753-760.

Frankel, J.A and A.Rose. (1998) "The Endogeneity of the Optimal Currency Area Criteria", Economic Journal, 108, 1009-25.

Frankel, J.A and A.Rose. (2001), "An Estimate of the Effect of Common Currencies on Trade and Income," JFK School of Government Working Paper \# RWP01013.

Fukao, K and X.Yue (2000), "Sengo Nihon Kokunai ni okeru Keizai Shusoku to Seisan Tounyu (Economic Convergence and Factor Endowments in post-war Japan)", Keizai Kenkyu vol. 51 No.2, 136-151, Japanese.

Fujita, M and T.Tabuchi (1997)“Regional Growth in Postwar Japan.” Regional Science and Urban Economics, 27(6), 643-70.

Gruben,W., Koo, J. and E.Mills (2002) "How much does international trade affect business cycle synchronization?”, Federal Reserve Bank of Texas Research Department Working Paper, 0203.

Harvey, A..C. and A. Jaeger (1993), "Detrending, stylized facts and the business cycle", Journal of Applied Econometrics, 8, 231-247.

Helpman, E. (1987), "Imperfect Competition and International Trade: Evidence from Fourteen Industrial Countries", Journal of the Japanese and International Economies, 1, 1, 62-81.

Helpman, E.M. and P. Krugman (1985) Market Structure and Foreign Trade, Cambridge, MIT Press.

Hess, G. D. and Shin, K. (1997). "International and intranational business cycles", Oxford Review of Economic Policy, Vol. 13, pp. 93-109.

Hess, G. D. and Shin, K. (2001). "Intranational business cycles in the United States," Journal of International Economics 44 (1998) 289-313 
H.M Treasury (2003) The United States as a Monetary Union, EMU Study.

Hummels, D. and J. Levinsohn (1995), "Monopolistic Competition and International Trade: Reconsidering the Evidence", Quarterly Journal of Economics, 110, 3, 797-836.

Imbs, J. (2004). “Trade, finance, specialization, and synchronization", Review of Economics and Statistics, 86, 723-34.

Inklaar, R., R. Jong-A-Pin and J.de Haan (2008) "Trade and business cycle synchronization in OECD countries-A re-examination” European Economic Review. 52, pp.646-665.

Iwamoto, Y., and E. V Wincoop. (2000) "Do Borders Matter?: Evidence from Japanese Regional Net Capital Inflows,” International Economic Review 41, 241-69.

Kaiser, R. and A Maravall (2001) Measuring Business Cycles in Economic Time Series, Lecture Notes in Statistics 154, New York: Springer-Verlag.

Kaiser, R. and A. Maravall (2002) A complete model-based interpretation of the Hodrick-Prescott filter: spuriousness reconsidered, at http://www.bde.es/servicio/software/tramo/mhpfmodel.pdf.

Kenen.P.B. (2000) Currency Areas, Policy Domains, and the institutionalization of Fixed Exchange Rates, at http://cep.lse.ac.uk/pubs/download/dp0467.pdf.

McCallum, J., (1995). "National borders matter: Canada-US regional trade patterns." American Economic Review, 85 (3), 615-623.

McKinnon, R. (1963). “Optimal Currency Areas.” American Economic Review, 53, September: 717-724.

Meyers, M. and P.Winker (2005) "Using HP filtered data for econometric analysis: some evidence from Monte Carlo simulations", Allgemeines Statistiches Archiv, 89: 303-320.

Moran, P.A.P. (1948) "The interpretation of statistical maps," Journal of the Royal Statistical Society. Series B 10: 243-251.

Moran, P.A.P. (1950). "Notes on continuous stochastic phenomena". Biometrika 37:17-23.

Mundell, R.A. (1961) “A Theory of Optimum Currency Areas”, American Economic Review, 51, 657-65.

Okubo, T (2004) "Border Effect in the Japanese Market -A gravity model analysis", Journal of the Japanese and International Economies 18, 1-11.

Partridge, M.D. and D.S. Rickman (2005) "Regional cyclical asymmetries in an Optimal Currency Area: an analysis using US State data", Oxford Economic Papers, 57, 373-397.

Ravn, M., and H. Uhlig (2002). "On Adjusting the HP Filter for the Frequency of Observations", Review of Economics and Statistics 84 (2): 371-376.

Rose, A K. (2000), "One Money, One Markets: Estimating the Effect of Common Currencies on Trade," Economic Policy: A European Forum, April, pp. 7-33.

Spolaore, E.and R. Wacziarg (2006) “Development and Diffusion”, CEPR DP 5639. 
Wincoop, E.V (1995), “Regional Risksharing”, European Economic Review, 39(8), $1545-67$.

Wynne, M., Koo, J., (2000). "Business Cycles under Monetary Union: a Comparison of the EU and US.", Economica 67, 347-374. 
Figure 1: GDP Cycles.

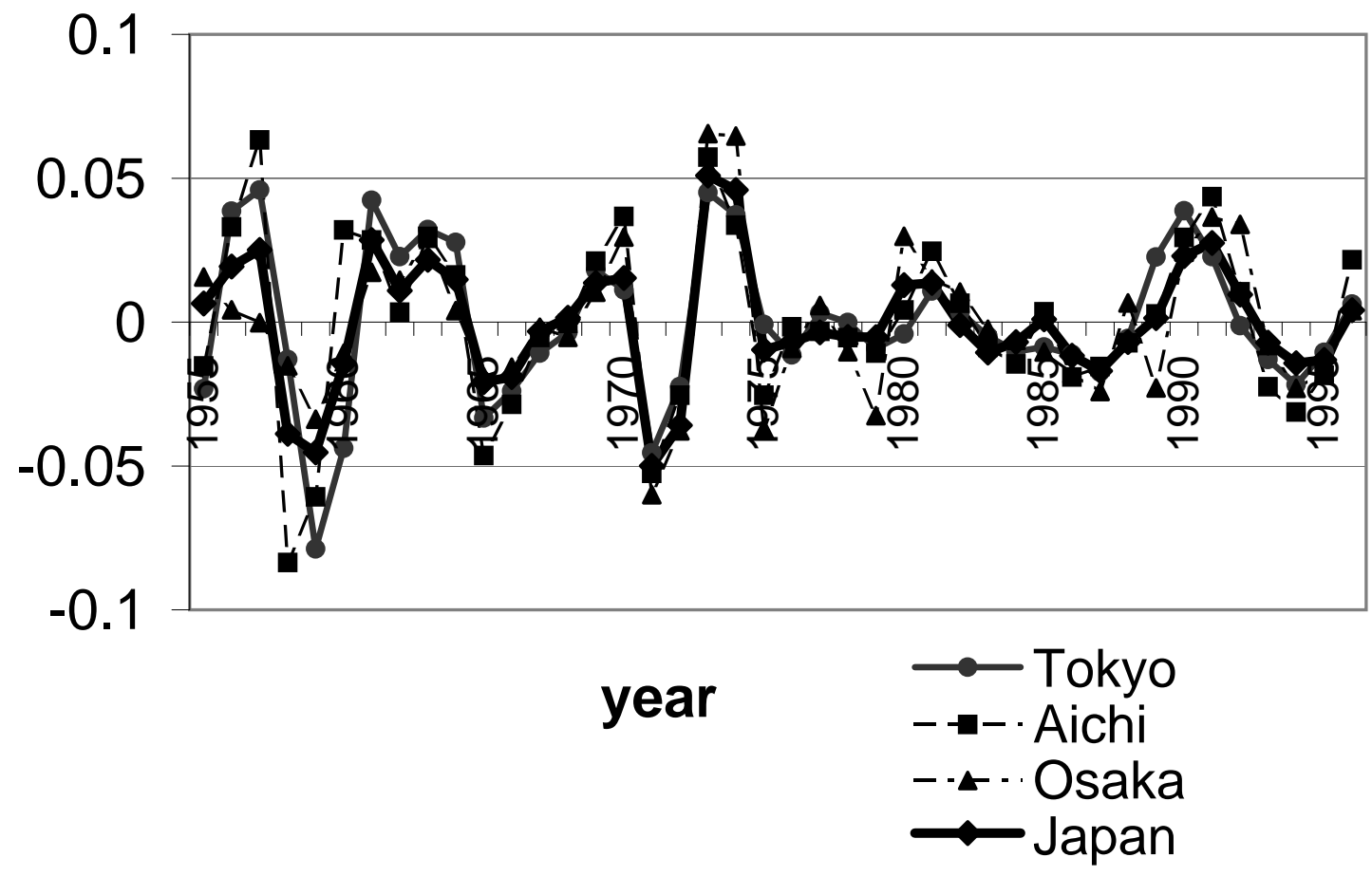


Figure 2: GDP Cross-correlations in the USA and Euro countries.

US states (1990-1997)
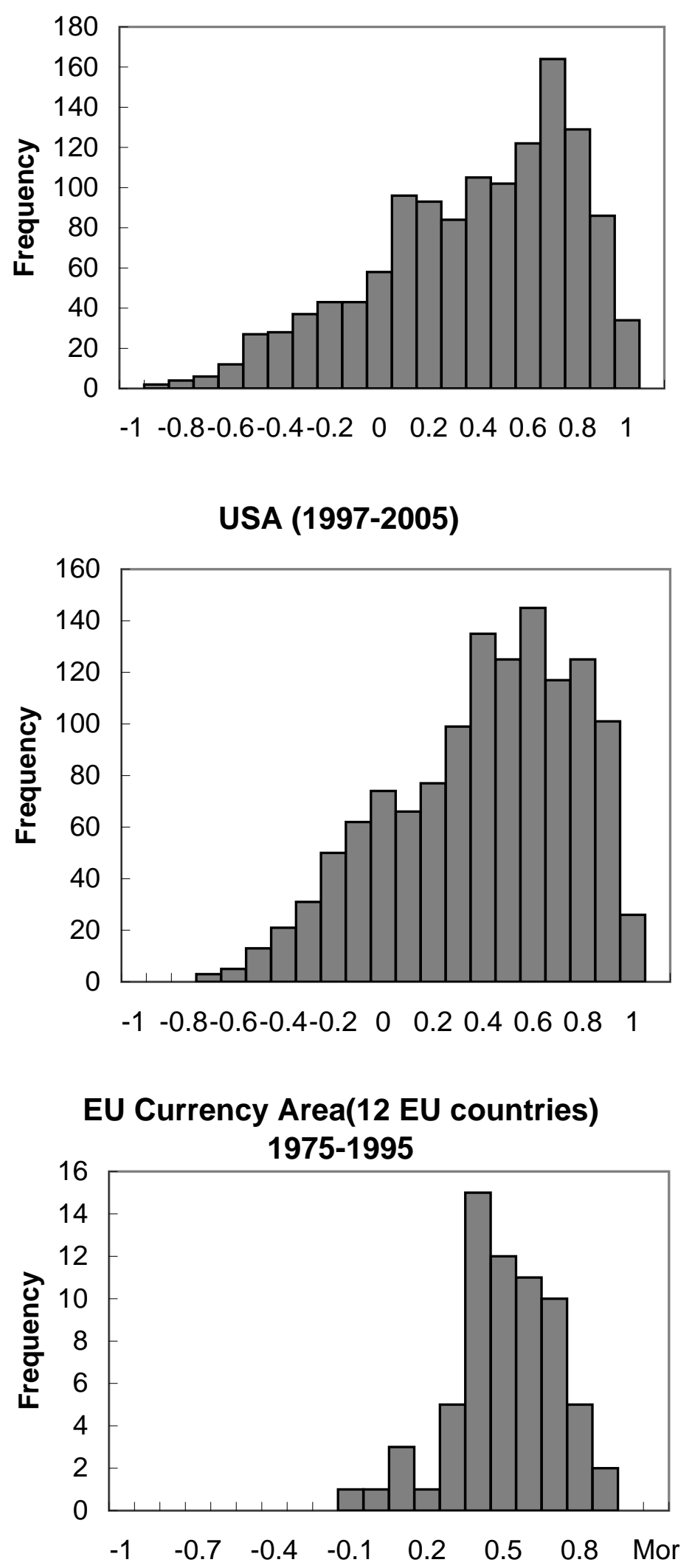
Figure 3: Japanese Prefecture GDP Cross-correlations.

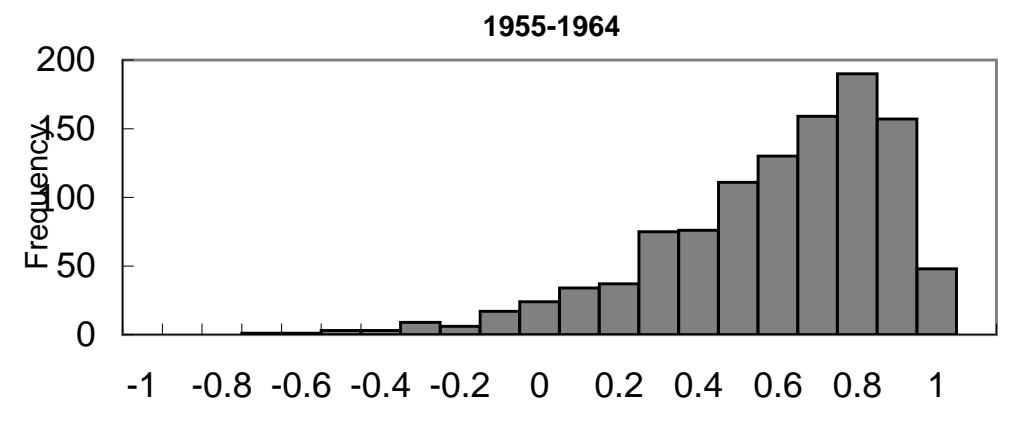

1965-1974
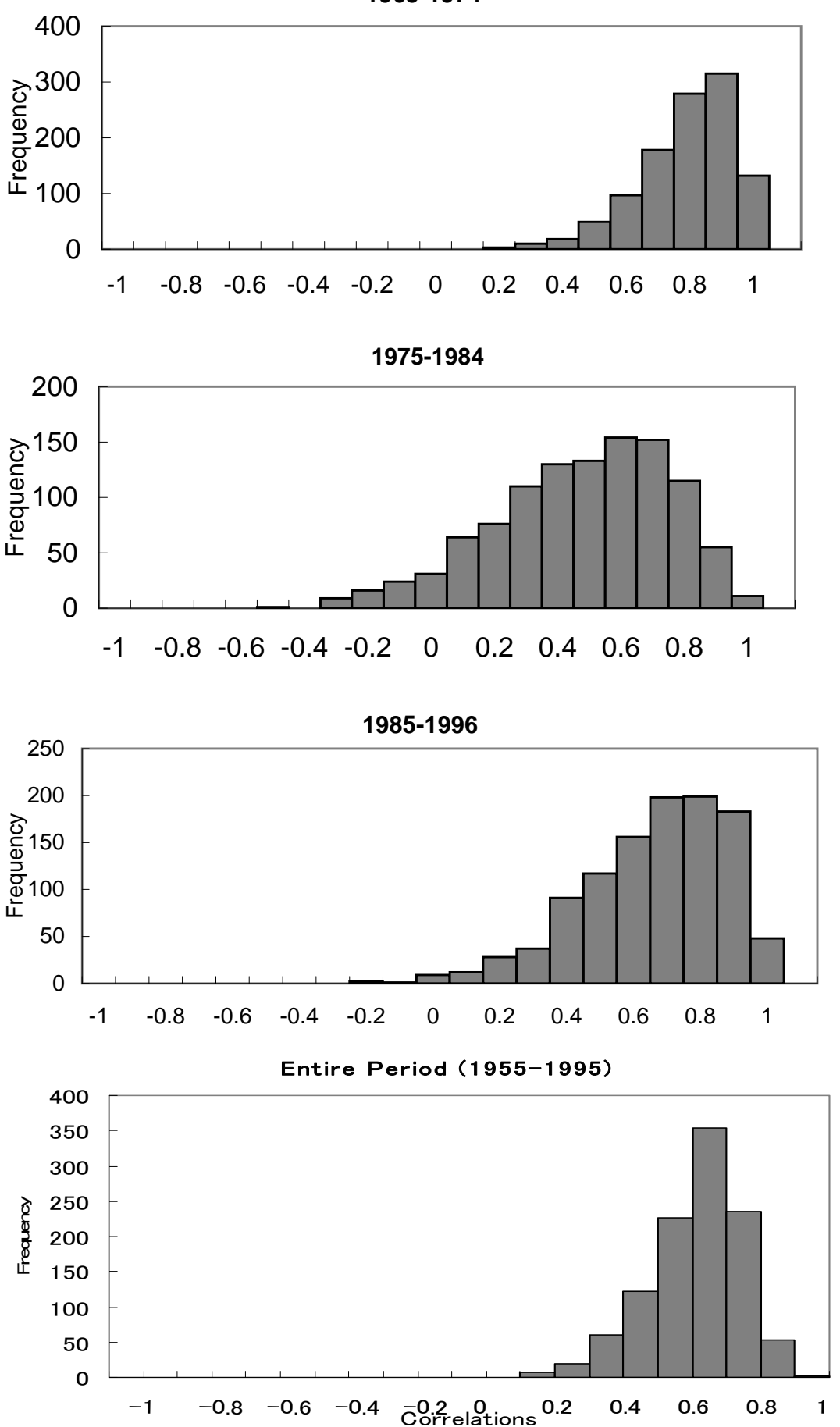
Figure4: Consumption Risk Sharing.

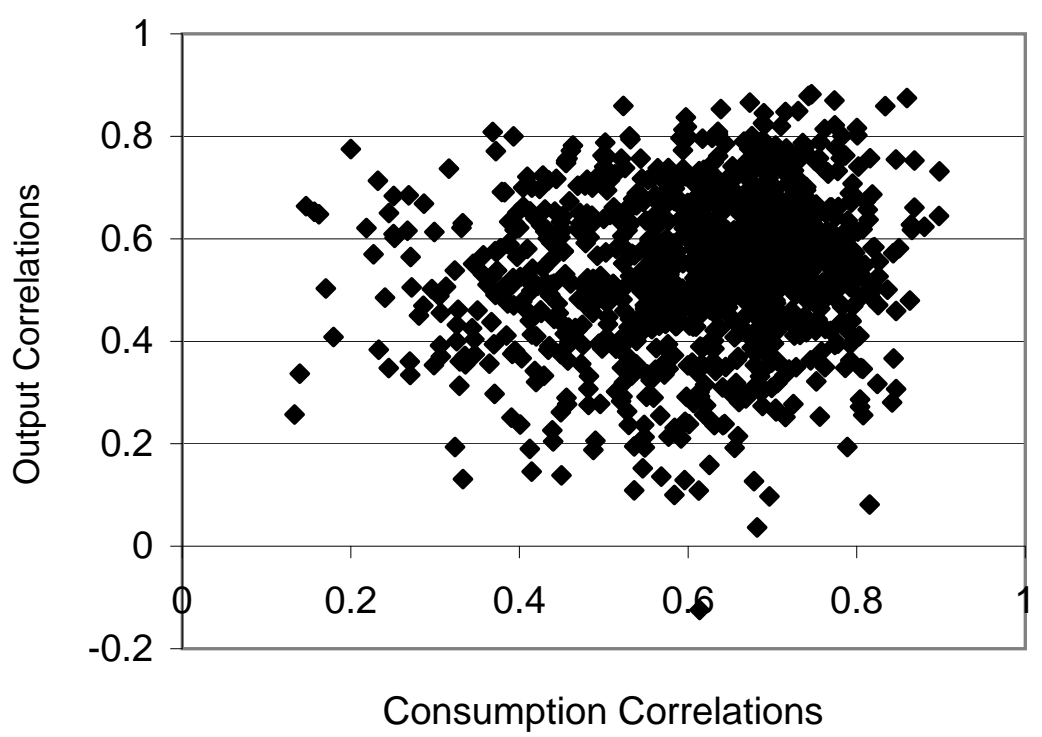

Figure A: Spatial Autocorrelations.

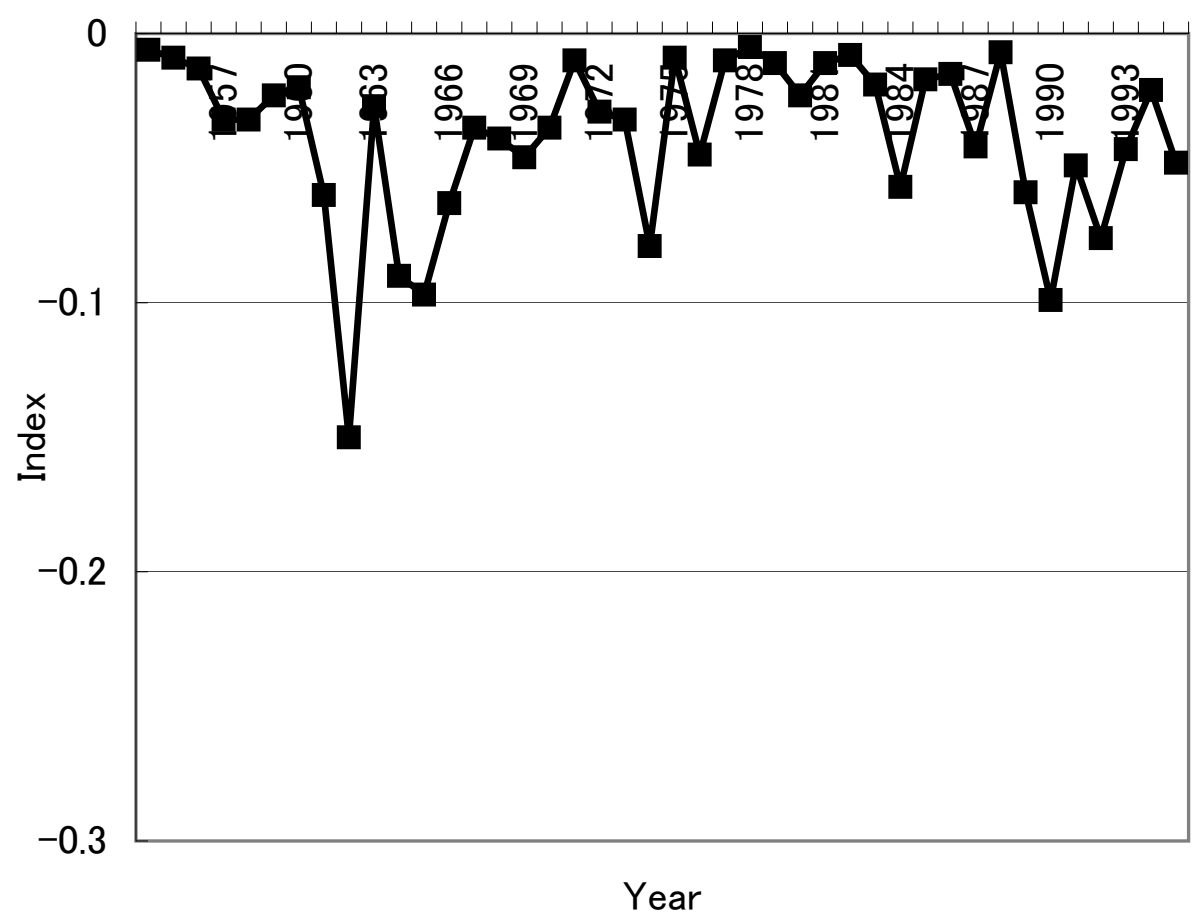

Note: The detrended GDP data are used. 
Classical Gravity Model

Table 1: GMM Results

\begin{tabular}{|c|c|c|c|c|c|c|}
\hline \multirow{5}{*}{$\begin{array}{l}\text { GDP } \\
\text { Neighbor } \\
\text { Dist }\end{array}$} & \multicolumn{2}{|l|}{$1965-1974$} & \multicolumn{2}{|l|}{ 1975-1984 } & \multicolumn{2}{|l|}{ 1985-1995 } \\
\hline & Coefficients & value & Coefficien & -value & Coefficient & value \\
\hline & 0.0840034 & $8.25 * *$ & 0.077148 & $8.26 * *$ & 0.042957 & $3.68 * *$ \\
\hline & -0.06482 & -1.31 & 0.093037 & $2.05 * *$ & 0.031013 & 0.53 \\
\hline & -0.119142 & $-6.74 * *$ & -0.01577 & -0.98 & 0.001381 & 0.07 \\
\hline Sample Size & 1035 & & 1035 & & 1035 & \\
\hline Underidentification & 1010.64 & & 1027.008 & & 1028.28 & \\
\hline Weak Identification & 43000 & & 130000 & & 160000 & \\
\hline Sargan Statistic & 0 & & 0 & & 0 & \\
\hline Centered R-sq & 0.1274 & & 0.0788 & & 0.0117 & \\
\hline Uncentered R-sq & 0.9071 & & 0.9153 & & 0.5183 & \\
\hline Root MSE & 0.3698 & & 0.3382 & & 0.4346 & \\
\hline
\end{tabular}

\section{Gravity Model}

\begin{tabular}{|c|c|c|c|c|c|c|}
\hline \multirow[b]{3}{*}{ GDP } & \multicolumn{2}{|l|}{$1965-1974$} & \multicolumn{2}{|c|}{$1975-1984$} & \multicolumn{2}{|l|}{ 1985-1995 } \\
\hline & Coefficients & value & Coefficien & -value & Coefficient & -value \\
\hline & 0.1078818 & $9.69 * *$ & 0.09609 & $9.12 * *$ & 0.084707 & $6.89 * *$ \\
\hline GDPcapita & -0.335064 & $-4.24 * *$ & -0.3385 & $-3.38 * *$ & -0.77129 & $-8.5 * *$ \\
\hline Area & -0.069792 & $-4.9 * *$ & 0.076505 & $5.73 * *$ & -0.01925 & -1.16 \\
\hline Neighbor & -0.026755 & -0.54 & 0.026524 & 0.59 & 0.01642 & 0.29 \\
\hline Dist & -0.079308 & $-4.23 * *$ & -0.05287 & $-3.14 * *$ & 0.010645 & 0.49 \\
\hline Sample Size & 1035 & & 1035 & & 1035 & \\
\hline Underidentification & 793.055 & & 591.645 & & 899.463 & \\
\hline Weak Identification & 1686.442 & & 686.586 & & 3414.375 & \\
\hline Sargan Statistic & 0 & & 0 & & 0 & \\
\hline Centered R-sq & 0.1692 & & 0.1361 & & 0.0775 & \\
\hline Uncentered R-sq & 0.9116 & & 0.9206 & & 0.5504 & \\
\hline Root MSE & 0.3608 & & 0.3275 & & 0.4199 & \\
\hline
\end{tabular}

Augmented Gravity Model and Factor Endowments

\begin{tabular}{|c|c|c|c|c|c|c|}
\hline \multirow[b]{3}{*}{ GDP } & \multicolumn{2}{|l|}{$1965-1974$} & \multicolumn{2}{|l|}{$1975-1984$} & \multicolumn{2}{|l|}{ 1985-1995 } \\
\hline & Coefficients & alue & Coefficien & value & Coefficient & value \\
\hline & 0.1114197 & $6.39 * *$ & 0.091824 & $6.9 * *$ & 0.070263 & $4.44 * *$ \\
\hline $\mathrm{KL}$ & 0.002736 & 1.23 & -0.00242 & $-2.69 * *$ & -0.00118 & $-2.11 * *$ \\
\hline Human & -0.093917 & -0.18 & -0.72558 & -1.51 & -2.26307 & $-3.19 * *$ \\
\hline Infra & -0.037291 & $-2.03 * *$ & 0.007213 & 0.52 & 0.003903 & 0.24 \\
\hline Area & -0.046838 & $-3.09 * *$ & 0.075612 & $5.53 * *$ & -0.00389 & -0.21 \\
\hline Neighbor & -0.039105 & -0.77 & 0.028083 & 0.62 & 0.020003 & 0.34 \\
\hline Dist & -0.097988 & $-5.16 * *$ & -0.05206 & $-3.08 * *$ & 0.008968 & 0.4 \\
\hline Sample Size & 1035 & & 1035 & & 1035 & \\
\hline Underidentification & 388.799 & & 541.381 & & 622.751 & \\
\hline Weak Identification & 154.478 & & 281.593 & & 387.852 & \\
\hline Sargan Statistic & 0 & & 0 & & 0 & \\
\hline Centered R-sq & 0.1387 & & 0.1363 & & 0.0369 & \\
\hline Uncentered R-sq & 0.9083 & & 0.9206 & & 0.5306 & \\
\hline Root MSE & 0.3674 & & 0.3275 & & 0.4291 & \\
\hline
\end{tabular}


Augmented Gravity Model with Industrial Structure 1

\begin{tabular}{|c|c|c|c|c|c|c|}
\hline \multirow[b]{3}{*}{ GDP } & \multicolumn{2}{|l|}{$1965-1974$} & \multicolumn{2}{|l|}{ 1975-1984 } & \multicolumn{2}{|l|}{ 1985-1995 } \\
\hline & \multicolumn{2}{|c|}{ Coefficients z-value } & \multicolumn{2}{|c|}{ Coefficientz-value } & \multicolumn{2}{|c|}{ Coefficientz-value } \\
\hline & 0.0685275 & $3.48 * *$ & 0.086918 & $6.54 * *$ & 0.069823 & $4.41 * *$ \\
\hline $\mathrm{KL}$ & 0.005841 & $2.54 * *$ & -0.00156 & $-1.66 *$ & -0.00126 & $-2.12 * *$ \\
\hline Human & 0.498021 & 0.91 & -0.37641 & -0.77 & -2.33988 & $-3.14 * *$ \\
\hline Infra & -0.047121 & $-2.56 * *$ & 0.00303 & 0.22 & 0.004604 & 0.28 \\
\hline CL & 8.454948 & $4.81 * *$ & 2.60363 & $2.85 * *$ & -0.37958 & -0.39 \\
\hline Area & 0.0124057 & 0.64 & 0.088293 & $6.19 * *$ & -0.00488 & -0.27 \\
\hline Neighbor & -0.00573 & -0.11 & 0.038473 & 0.86 & 0.018688 & 0.32 \\
\hline Dist & -0.068214 & $-3.4 * *$ & -0.04318 & $-2.53 * *$ & 0.007916 & 0.35 \\
\hline Sample Size & 1035 & & 1035 & & 1035 & \\
\hline Underidentification & 389.662 & & 538.641 & & 617.384 & \\
\hline Weak Identification & 123.902 & & 222.68 & & 303.358 & \\
\hline Sargan Statistic & 0 & & 0 & & 0 & \\
\hline Centered R-sq & 0.1318 & & 0.1477 & & 0.0368 & \\
\hline Uncentered R-sq & 0.9076 & & 0.9216 & & 0.5306 & \\
\hline Root MSE & 0.3688 & & 0.3253 & & 0.4291 & \\
\hline
\end{tabular}

\section{Augmented Gravity Model with Industrial Structure 2}

\begin{tabular}{|c|c|c|c|c|c|c|}
\hline \multirow[b]{3}{*}{ GDP } & \multicolumn{2}{|l|}{$1965-1974$} & \multicolumn{2}{|l|}{$1975-1984$} & \multicolumn{2}{|l|}{$1985-1995$} \\
\hline & \multicolumn{2}{|c|}{ Coefficients z-value } & \multicolumn{2}{|c|}{ Coefficient $z$-value } & \multicolumn{2}{|c|}{ Coefficientz-value } \\
\hline & 0.0229844 & 1.2 & 0.062653 & $4.63 * *$ & 0.071228 & $4.43 * *$ \\
\hline $\mathrm{KL}$ & 0.0061484 & $2.84 * *$ & -0.00131 & -1.48 & -0.00122 & $-2.16 * *$ \\
\hline Human & 0.7354466 & 1.39 & -0.02021 & -0.04 & -2.32725 & $-3.19 * *$ \\
\hline Infra & -0.040983 & $-2.31 * *$ & 0.002949 & 0.22 & 0.003974 & 0.24 \\
\hline CV & 1.899804 & $10.35 * *$ & 1.119015 & $6.81 * *$ & -0.09323 & -0.42 \\
\hline Area & 0.0164076 & 1.03 & 0.101541 & $7.39 * *$ & -0.0049 & -0.27 \\
\hline Neighbor & 0.0421626 & 0.85 & 0.068099 & 1.55 & 0.017607 & 0.3 \\
\hline Dist & -0.023269 & -1.18 & -0.01435 & -0.83 & 0.006428 & 0.28 \\
\hline Sample Size & 1035 & & 1035 & & 1035 & \\
\hline Underidentification & 388.58 & & 540.359 & & 622.649 & \\
\hline Weak Identification & 123.351 & & 224.166 & & 309.851 & \\
\hline Sargan Statistic & 0 & & 0 & & 0 & \\
\hline Centered R-sq & 0.1922 & & 0.191 & & 0.0375 & \\
\hline Uncentered R-sq & 0.914 & & 0.9256 & & 0.5309 & \\
\hline Root MSE & 0.3558 & & 0.3169 & & 0.4289 & \\
\hline
\end{tabular}

Notes

Constant terms, prefecture dummies and time dummies are omitted.

* significant at the 10 per cent level.

** significant at the 5 per cent level.

Independent variables are Fisher z-transformed cross-correlations of HP filtered GDPs.

Instrumental variables are one period lags of all independent variables.

All variables in the period of 1955-1964 are used as instrumental variables for 1965-1974.

There are no estimations for the first period because no data is available for a lagged period (before 1955). 
Table 2: Regional Panel Regressions

\begin{tabular}{lrrrrrr} 
& \multicolumn{2}{c}{1} & \multicolumn{2}{c}{2} & \multicolumn{2}{c}{3} \\
\hline GDP & Coefficients & t-value & Coefficients & t-value & Coefficients t-value \\
GDPcapita & 0.1540276 & $3.3 * *$ & & & & \\
Dist & -0.1019627 & $-2.12 * *$ & & & & \\
Trade & -0.1032499 & -1.34 & & & & \\
TradeIntensity & & & 6.783852 & $4.54 * *$ & & \\
Area & -0.0753554 & -0.83 & -0.0252396 & -0.36 & -0.100572 & -1.34 \\
\hline Number of Samp & 84 & & 84 & & 84 \\
R-squared & 0.515 & & 0.4884 & & 0.3481
\end{tabular}

Constant terms, prefecture dummies and time dummies are omitted.

* significant at the 10 per cent level.

** significant at the 5 per cent level.

Independent variables are Fisher $z$-transformed cross-correlations of HP filtered GDPs.

Instrumental variables are one period lags of all independent variables. 
Table A: Japanese Prefectures and Regions.

\begin{tabular}{|c|c|}
\hline Code & Prefecture Name \\
\hline 1 & Hokkaido \\
\hline 2 & Aomori \\
\hline 3 & Iwate \\
\hline 4 & Miyagi \\
\hline 5 & Akita \\
\hline 6 & Yamagata \\
\hline 7 & Fukushima \\
\hline 8 & Ibaraki \\
\hline 9 & Tochigi \\
\hline 10 & Gunma \\
\hline 11 & Saitama \\
\hline 12 & Chiba \\
\hline 13 & Tokyo \\
\hline 14 & Kanagawa \\
\hline 15 & Niigata \\
\hline 16 & Toyama \\
\hline 17 & Ishikawa \\
\hline 18 & Fukui \\
\hline 19 & Yamanashi \\
\hline 20 & Nagano \\
\hline 21 & Gifu \\
\hline 22 & Sizuoka \\
\hline 23 & Aichi \\
\hline 24 & Mie \\
\hline 25 & Shiga \\
\hline 26 & Kyoto \\
\hline 27 & Osaka \\
\hline 28 & Hyougo \\
\hline 29 & Nara \\
\hline 30 & Wakayama \\
\hline 31 & Tottori \\
\hline 32 & Shimane \\
\hline 33 & Okayama \\
\hline 34 & Hiroshima \\
\hline 35 & Yamaguchi \\
\hline 36 & Tokushima \\
\hline 37 & Kagawa \\
\hline 38 & Ehime \\
\hline 39 & Kouchi \\
\hline 40 & Fukuoka \\
\hline 41 & Saga \\
\hline 42 & Nagasaki \\
\hline 43 & Kumamoto \\
\hline 44 & Oita \\
\hline 45 & Miyazaki \\
\hline 46 & Kagoshima \\
\hline 47 & Okinawa \\
\hline
\end{tabular}

\begin{tabular}{|r|l|l|}
\hline Region & Region name & Prefectures \\
\hline 1 & Hokkaido & Hokkaido \\
2 & Tohoku & Aomori, Iwate, Miyagi, Akita, Yamagata, Fukushima \\
3 & Kanto & $\begin{array}{l}\text { Ibaraki, Tochigi, Gunma, Saitama, Chiba, Tokyo } \\
\end{array}$ \\
4 & Kanabu & Kichi, Gifu, Ishikawa, Toyama, Mie \\
5 & Kinki & Nara, Shiga, Kyoto, Osaka, Hyogo, Fukui, Wakayama \\
6 & Chugoku & Tottori, Shimane, Okayama, Hiroshima, Yamaguchi \\
7 & Shikoku & Kagawa, Tokushima, Kochi, Ehime \\
8 & Kyushu & Fukuoka, Saga, Oita,Nagasaki, Kumamoto, Miyazaki \\
& & \\
\hline
\end{tabular}

